\title{
Tumor-Associated Vasculature
}

National Cancer Institute

\section{Source}

National Cancer Institute. Tumor-Associated Vasculature. NCI Thesaurus. Code C12968.

New blood vessels formed by solid tumors. 